\title{
Dash for DOT
}

$\mathrm{T}$ HE PAST DECADE has BROUGHT A RESURgENCE OF ATTENTION from both health professionals and the public on tuberculosis. Much of the attention has been fuelled in the United States by the increase in cases of tuberculosis, which began in 1985 after 35 years of steadily declining incidence (1). In the United States, the majority of the excess tuberculosis cases occurs in those co-infected with human immunodeficiency virus (HIV) (1). A decline in the level of funding of public health programs in the United States is undoubtedly a contributing factor (2). Most alarming about the upsurge in American cases of tuberculosis is the increasing prevalence of drug resistance (3), particularly combined isoniazid and rifampin resistance, also known as multidrug resistant tuberculosis (MDR-TB). MDR-TB has been seen predominantly in the HIV co-infected population within the United States and is associated with high mortality rates and low cure rates (3).

In Canada, there have also been changes in the epidemiology of tuberculosis. The number of tuberculosis cases in Canada continued to fall until 1989, when there was an increase, with a plateau in subsequent years. In contrast to the American situation, the increase in Canadian cases is not significantly attributable to HIV co-infection, but rather to an increase in cases in foreign-born individuals. In fact, approximately $60 \%$ of all cases of tuberculosis in Canada occur in the foreign-born. There has also been some concern about MDR-TB in Canada (4), although most of these cases have not occurred in the HIV co-infected and outbreaks similar to those seen in the United States have not been described.

In order to respond to the current tuberculosis epidemic, several strategies have been proposed $(5,6)$. One strategy that is widely accepted is the routine performance of in vitro susceptibility on ALL isolates of Mycobacterium tuberculosis to identify drug resistance. Ideally, this should be by rapid methods (eg, radiometric) to identify resistance as promptly as possible. The second strategy is the routine use of more drugs (often four) for initial therapy, rather than fewer drugs, until susceptibility results are known. This principle applies most strongly to individuals who have previously received antituberculous therapy and to those epidemiologically linked to confirmed resistant isolates, next to the foreign-born and lastly to previously untreated Canadian-born patients. The third strategy is the use of directly observed therapy (DOT). DOT refers to the practice of ensuring that all doses of medications are taken and swallowed in the presence of a trained observer (7). DOT is based on several premises. First, antituberculous therapy is highly effective provided a complete course is taken. Second, previous studies have consistently demonstrated that physicians are unable to predict accurately which patients will be adherent with therapy (8). Third, DOT will prevent or markedly reduce the incidence of acquired drug resistance (9), since patients will not be able to discontinue some of their anituberculous agents selectively. The high efficacy of twice-weekly dosing regimens for the treatment of tuberculosis has made DOт feasible.

Although there is widespread support for the practice of DOT for some patients, whether DOT should be used routinely for all patients remains controversial $(10,11)$. Arguments against routine DOT include the fact that a variable proportion of patients will be adherent with their medication and DOT is unnecessary for that group. The second argument is that DOT is expensive to administer. The third argument is that DOT may be an infringement of civil liberties in certain jurisdictions (12).

With respect to the first argument, there is no question that there is a substantial group of individuals who would be adherent with antituberculous medications. Nevertheless, experience has demonstrated that it is not possible to identify these patients (8). Whereas the implementation of universal DOT can be argued as unnecessary for those individuals who would be adherent, an analogy with immunization can be drawn. In the absence of immunization programs, not all individuals would develop tetanus, polio or any of the other common infections for which routine immunization is recommended. Nevertheless, it is standard practice to immunize the entire population, since it is impossible to identify which individuals will subsequently become at risk. Furthermore, with respect to immunization, there is the added benefit of herd immunity conferred to the minority of the population who do not respond to vaccine. An analogous situation to herd immunity may occur with an effective tuberculosis control program. If active cases are cured with an effective tuberculosis control program such as DOT, then individuals not infected with tuberculosis when source patients are treated will also be protected indirectly by the successful cure of source patients. The recent reduction of new cases of tuberculosis in New York City has largely been attributed to the increased use of DOT (13).

The economic benefits of DOT are overwhelming. Although there are upfront costs required to implement a DOT program, DOT has been shown to reduce markedly the rate of drug resistance and relapse in tuberculosis (9). A recent report from Denver has found that the cost of treating a single case of MDR-TB can be us $\$ 180,000$ (14). Accordingly, it is estimated that the cost of treatment of a single case of MDR-TB can deliver DOT to approximately 700 patients (15). There is no doubt that DOT is not only cost effective, but that DOT will prevent additional morbidity and mortality by preventing secondary 
cases. Furthermore, the cost of DOT programs can be lower than that of most other programs. Most programs have continued to rely on nurses to administer DOT $(9,11)$. However, others have demonstrated that DOT is equally effective when administered by nonhealth professionals (16) with similar low rates of loss to follow-up. Whereas it may be ideal to have the expertise of a nurse or other health professional at each DOT session, it is not essential and health care dollars can be utilized more wisely by using nonhealth professionals who have been adequately trained. The implementation of DOT with nonhealth professionals does not replace regular (approximately monthly) clinic visits with clinical, bacteriological and radiographic follow-up.

The case for routine DOT is compelling. It is now time to implement DOT, perhaps initially in a perceived higher risk patient population, but the ultimate goal in the very near future should be for a policy of $100 \%$ DOT for all cases of active tuberculosis. Once this is accomplished, it will be time to evaluate DOT for isoniazid preventive therapy, the benefits of which have not yet been established.

\section{REFERENCES}

1. Bloom BR, Murray CJL. Tuberculosis: commentary on a reemergent killer. Science 1992;257:1055-64.

2. Brudney K, Dobkin J. Resurgent tuberculosis in New York City. Human immunodeficiency virus, homelessness, and the decline of tuberculosis control programs. Am Rev Respir Dis 1991;144:745-9.

3. Centers for Disease Control. National action plan to combat multidrug-resistant tuberculosis; meeting the challenge of multidrug-resistant tuberculosis: summary of a conference; management of persons exposed to multidrug-resistant tuberculosis. MMWR 1992;41(RR-11).

4. Long R, Manfreda J, Mendella L, Wolfe J, Parker S, Hershfield E. Antituberculous drug resistance in Manitoba from 1980-1989. Can Med Assoc J 1993;148:1489-95.
5. Advisory Council for the Elimination of Tuberculosis. Initial therapy for tuberculosis in the era of multidrug resistance: recommendations of the Advisory Council for the Elimination of Tuberculosis. MMWR 1993;42(RR/7).

6. Laboratory Centre for Disease Control. Tuberculosis Prevention and Control: Proceedings and Recommendations. Ottawa: Health Canada, Health Protection Branch, 1995:1-32.

7. Bayer R, Wilkinson D. Directly observed therapy for tuberculosis: history of an idea. Lancet 1995;345:1545-8.

8. Sumartojo E. When tuberculosis treatment fails. A social behavioral account of patient adherence. Am Rev Respir Dis 1993;147:1311-20.

9. Weis SE, Slocum PC, Blais FX, et al. The effect of directly observed therapy on the rates of drug resistance and relapse in tuberculosis. N Engl J Med 1994;330:1179-84.

10. Nardell EA. Beyond four drugs. Public health policy and the treatment of the individual patient with tuberculosis. Am Rev Respir Dis 1993;148:2-5.

11. Schluger N, Ciotoli C, Cohen D, Johnson H, Rom WN. Comprehensive tuberculosis control for patients at high risk for noncompliance. Am J Respir Crit Care Med 1995;151:1486-90.

12. Annas GJ. Control of tuberculosis - the law and the public's health. N Engl J Med 1993;328:585-8.

13. Frieden TR, Fujiwara PI, Washko RM, Hamburg MA. Tuberculosis in New York City - turning the tide. N Engl J Med 1995;333:229-33.

14. Mahmoudi A, Iseman MD. Pitfalls in the care of patients with tuberculosis. Common errors and their association with the acquisition of drug resistance. JAMA 1993;270:65-8.

15. Iseman MD, Cohn DL, Sbarbaro JA. Directly observed treatment of tuberculosis. We can't afford not to try it. N Engl J Med 1993;328:576-8.

16. Wilkinson D. High-compliance tuberculosis treatment programme in a rural community. Lancet 1994;343:647-8.

SD Shafran MD FRCPC Edmonton, Alberta JM Conly MD FRCPC Toronto, Ontario 


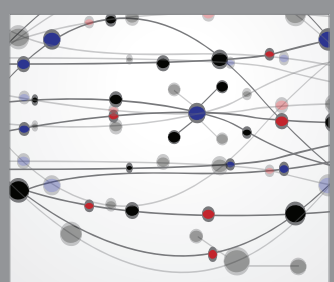

The Scientific World Journal
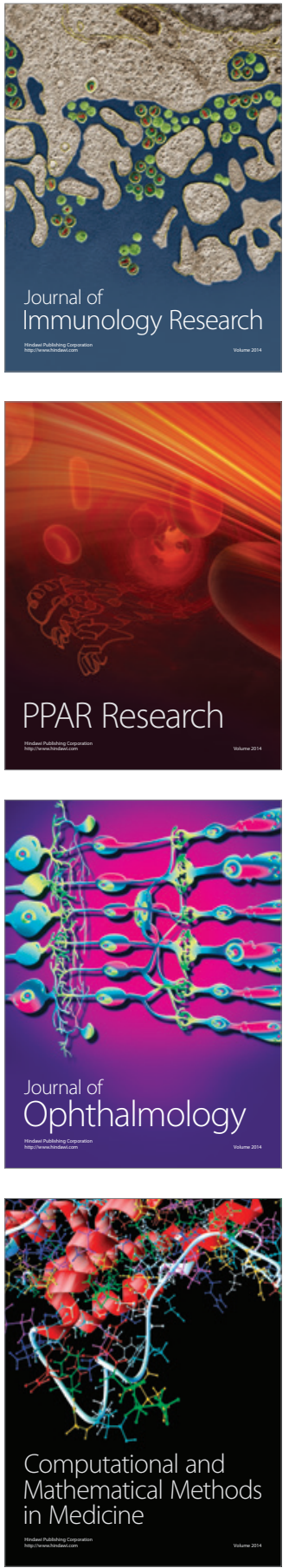

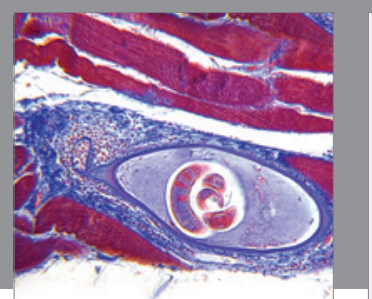

Gastroenterology Research and Practice

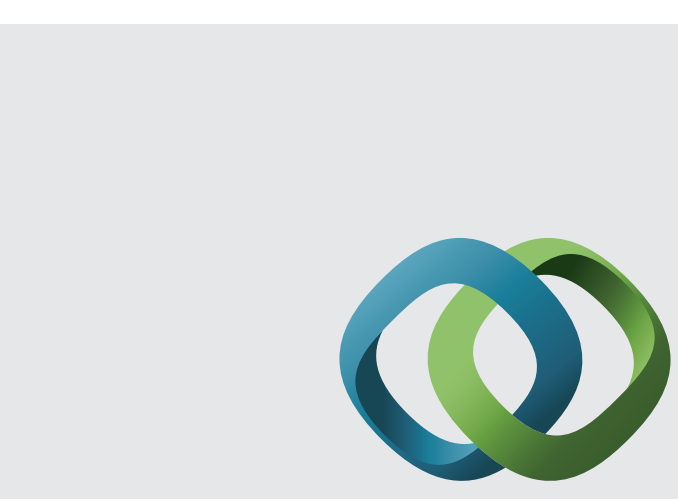

\section{Hindawi}

Submit your manuscripts at

http://www.hindawi.com
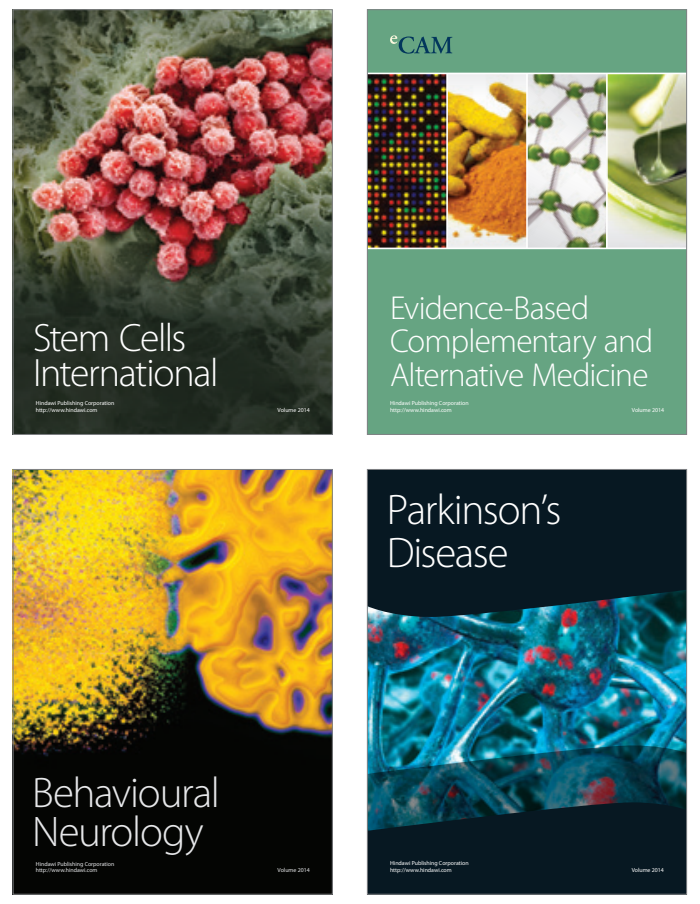
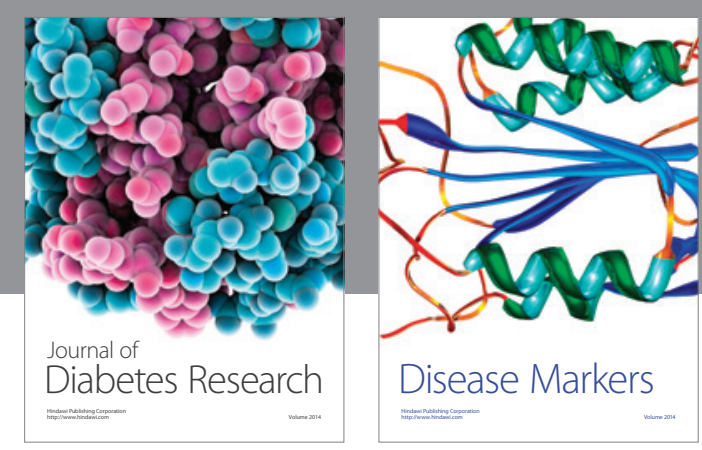

Disease Markers
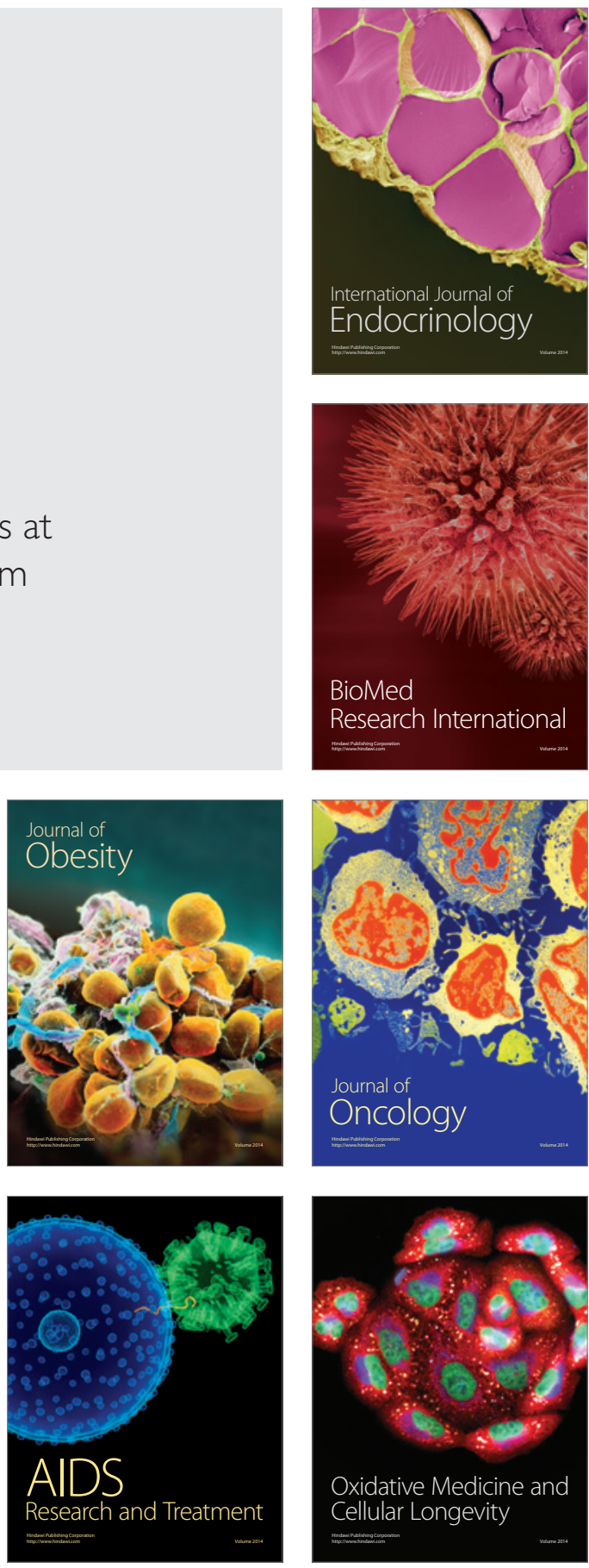